\title{
Lusioersily
}

\section{Formal Quantum Efficiencies for the Photocatalytic Reduction of CO2 in a Gas Phase Batch Reactor}

Cortes, M. A., Hamilton, J., Sharma, P., Brown, A., Nolan, M., Gray, K. A., \& Byrne, J. (2019). Formal Quantum Efficiencies for the Photocatalytic Reduction of CO2 in a Gas Phase Batch Reactor. Catalysis Today, 326, 7581. https://doi.org/10.1016/j.cattod.2018.10.047

Link to publication record in Ulster University Research Portal

Published in:
Catalysis Today

Publication Status:

Published (in print/issue): 01/04/2019

DOI:

10.1016/j.cattod.2018.10.047

\section{Document Version}

Author Accepted version

\section{General rights}

Copyright for the publications made accessible via Ulster University's Research Portal is retained by the author(s) and / or other copyright owners and it is a condition of accessing these publications that users recognise and abide by the legal requirements associated with these rights.

\section{Take down policy}

The Research Portal is Ulster University's institutional repository that provides access to Ulster's research outputs. Every effort has been made to ensure that content in the Research Portal does not infringe any person's rights, or applicable UK laws. If you discover content in the Research Portal that you believe breaches copyright or violates any law, please contact pure-support@ulster.ac.uk. 
Title: Formal Quantum Efficiencies for the Photocatalytic Reduction of $\mathrm{CO}_{2}$ in a Gas Phase Batch Reactor

Authors: M.A.L.R.M. Cortes ${ }^{\star a}$, J.W.J. Hamilton ${ }^{a}$, P.K. Sharma ${ }^{a}$, A. Brown ${ }^{a}$, M. Nolan ${ }^{b}$, K.A. Gray $^{\mathrm{c}}$, J.A. Byrne ${ }^{\mathrm{a}}$.

aNIBEC, Ulster University, Newtownabbey, BT37 0QB, UK

bTyndall National Institute, University College Cork, Lee Maltings, Cork, Ireland

'Northwestern University, 2145 Sheridan Road, Evanston, IL 60208, USA

${ }^{*}$ Corresponding author: $\underline{\text { Cortes-MA@ulster.ac.uk }}$

\section{Abstract}

The photocatalytic reduction of $\mathrm{CO}_{2}$ to fuels, or useful products, is an area of active research. In this work, nanoengineering and surface modification of titania were investigated as approaches for improving the $\mathrm{CO}_{2}$ reduction efficiency in a fixed-bed gas phase batch photoreactor under UV-Vis irradiation. Titania nanotubes were prepared by a hydrothermal method, and $\mathrm{TiO}_{2}$ (P25) was surface modified with copper clusters. Unmodified $\mathrm{TiO}_{2}$ (P25) was used as the bench-mark comparison. The titania nanotubes and $\mathrm{Cu}-\mathrm{TiO}_{2}$ materials showed higher efficiency for the photocatalytic reduction of $\mathrm{CO}_{2}$ to yield $\mathrm{CH}_{4}$ as compared to P25. Carbon monoxide yields were similar for all photocatalysts tested. The photocatalytic reduction of $\mathrm{CO}_{2}$ was observed on all photocatalyst tested, with the nanotubes proving to be the most efficient for the production of $\mathrm{CH}_{4}$. The product yields per mass of catalyst observed in this work are similar to those reported in the literature (with similar reactor parameters) but the calculated formal quantum efficiencies for $\mathrm{CO}_{2}$ reduction are very low $\left(4.41 \times 10^{-5}\right.$ to $\left.5.95 \times 10^{-4}\right)$.

Keywords: $\mathrm{CO}_{2}$ photoreduction, titanium dioxide, GC-MS controls, mechanism, quantum efficiency

\section{Research highlights}

Hydrothermal titania nanotubes, $\mathrm{Cu}$ modified $\mathrm{TiO}_{2}$ and $\mathrm{TiO}_{2} \mathrm{P} 25$ tested for the photocatalytic reduction of $\mathrm{CO}_{2}$ in a batch gas phase photoreactor

$\mathrm{CH}_{4}$ and $\mathrm{CO}$ were observed as the main products of photocatalytic reduction of $\mathrm{CO}_{2}$

$\mathrm{CO}_{2}$ reduction efficiencies in terms of product yield per gram of catalyst correlate to the literature

Formal quantum efficiencies for $\mathrm{CO}_{2}$ reduction are low.

Titania nanotubes give much better yield for $\mathrm{CH}_{4}$ as compared to $\mathrm{Cu}-\mathrm{TiO}_{2}$ and $\mathrm{P} 25$ 


\section{Introduction/ background}

Global warming and climate change are of major concern to humanity and the environment, with $\mathrm{CO}_{2}$ being the predominant greenhouse gas responsible for global warming. In order to reduce the levels $\mathrm{CO}_{2}$ emitted to the atmosphere, one can employ capture and utilisation, and artificial photosynthesis is a potential route to converting $\mathrm{CO}_{2}$ to fuels or useful chemicals. The photo-driven reduction of $\mathrm{CO}_{2}$ into fuels and/or platform chemicals has been reported using heterogeneous photocatalysis with a range of different photocatalytic materials and different reactor geometries and conditions which affect observed product distributions [1, 2]. $\mathrm{CO}_{2}$ photoreduction products including $\mathrm{CH}_{4}, \mathrm{CH}_{3} \mathrm{OH}, \mathrm{CO}$, small organic acids and, occasionally some higher carbon products, have all been reported for photocatalytic $\mathrm{CO}_{2}$ reduction [3].

The ability to control the product distribution and yield from photocatalytic $\mathrm{CO}_{2}$ reduction systems is a research target. Some platform chemicals e.g. $\mathrm{CO}, \mathrm{HCOOH}$ etc. are more valuable than solar fuels e.g. $\mathrm{CH}_{4}, \mathrm{CH}_{3} \mathrm{OH}$, and may represent a better product targets for synthesis [4]. To switch product distribution towards a desired product, reaction conditions are controlled to limit undesirable reactions or promote a reaction leading to a desired product [5].

Titanium dioxide $\left(\mathrm{TiO}_{2}\right)$ is the most commonly used research photocatalyst due to its comparatively good photocatalytic activity. Since $\mathrm{TiO}_{2}$ has a low solar efficiency due to its wide band gap requiring UV excitation, metal modification of the parent titania has been studied as a means to achieving the photocatalytic reduction of $\mathrm{CO}_{2}[1,6]$. The presence of carbonaceous surface species was found by some groups to complicate the results of isotopic ${ }^{13} \mathrm{CO}_{2}$ photoreduction studies, the rationale being that if ${ }^{13} \mathrm{C}$ labelled $\mathrm{CO}_{2}$ was the used, ${ }^{13} \mathrm{C}$ products would confirm the $\mathrm{CO}_{2}$ as the source of photocatalytic products. Considering the literature, using a range of photocatalytic materials, some studies showed mixed products [7-13], with only a few reporting solely ${ }^{13} \mathrm{C}$ products [14-17]. The observation of ${ }^{12} \mathrm{C}$ products in isotope studies are often assumed to be from surface contaminants, resulting in some authors questioning if the products and yields reported in other photoreduction studies, were due to contaminant oxidation, rather than true $\mathrm{CO}_{2}$ conversion $[7,18]$. Studies from a range of laboratories have used ${ }^{13} \mathrm{CO}_{2}$ to confirm $\mathrm{CO}_{2}$ as the source of methane, methanol, $\mathrm{CO}$ etc. produced by photocatalysis [9, 12, 14]. Given the potential for differing kinetics with isotopically labelled samples and the complexity/availability of GCMS, it has been recommended that researchers utilise a control run in the absence of $\mathrm{CO}_{2}$ instead of isotopically labelled ${ }^{13} \mathrm{C}$ as evidence against photo-Kolbe / side reactions as the source of $\mathrm{CO}_{2}$ reduction products $[19,20]$. However, efforts to eliminate $\mathrm{CO}_{2}$ prior to photoreduction experiments can be far from trivial due to pre-adsorption on catalyst surfaces [21] and unwanted traces of $\mathrm{CO}_{2}$ dissolved in liquid water.

There is some difficulty in comparing results of photocatalytic $\mathrm{CO}_{2}$ reduction studies reported due to variations in reactors and parameters. $\mathrm{CO}_{2}$ reduction yields are usually reported in $\mu \mathrm{mol} \mathrm{h} \mathrm{h}^{-1} \mathrm{~g}^{-1}$ of catalyst, however, this normalisation to per gram of catalyst can often be misleading [22]. Therefore, it is important to report the results in terms of photonic efficiency or formal quantum efficiency, which consider the irradiance and two dimensional area of catalyst. Very few researchers present photonic or formal quantum efficiency [23-27]. Nguyen et al. reported $1.86 \mu \mathrm{mol} \mathrm{h} \mathrm{h}^{-1} \mathrm{~g}^{-1}$ of methane and an overall quantum efficiency of $0.05 \%$ [28], and Collado and co-workers reported $0.4 \mu \mathrm{mol} \mathrm{h}^{-1} \mathrm{~g}^{-1}$ of methane but with an 
apparent quantum efficiency of $2.7 \%$ [29]. The comparison of rates per gram of catalyst is not possible without considering the irradiance and the emission spectrum of the source. A similar comparison can be made between the work of Tseng at al. and Tahir et al. regarding methanol production [22, 30].

This study aims to evaluate the photocatalytic reduction of $\mathrm{CO}_{2}$ in a gas phase batch reactor with well-defined reactor parameters, including the irradiance and emission spectrum of the source. A range of different photocatalytic materials were tested to determine differences in yield of products and their formal quantum efficiencies.

\section{Materials and Methods}

\subsection{Catalyst Preparation}

Three catalyst preparations were used in this study; unmodified $\mathrm{TiO}_{2}$ (Evonik Aeroxide P25), $\mathrm{Cu}$ modified $\mathrm{TiO}_{2}$ (P25) and $\mathrm{TiO}_{2}$ nanotubes. Cu clusters, used for surface modification, were synthesized by adapting the Brust-Schiffrin protocol [31]. For the $1.0 \mathrm{wt} \%$ copper/titanium dioxide catalyst (denoted $\mathrm{Cu}-\mathrm{TiO}_{2}$ ), $1 \mathrm{wt} \%$ synthesized $\mathrm{Cu}$ clusters were mixed with $\mathrm{TiO}_{2}$ (P25) by sonication in methanol followed by annealing at $550^{\circ} \mathrm{C}$. $\mathrm{TiO}_{2}$ nanotubes (denoted NT) were prepared by a hydrothermal method previously reported [32]. The catalyst powders were immobilised on borosilicate glass plates $(25 \mathrm{~mm} \times 20 \mathrm{~mm})$ by spray coating until the desired weight was obtained $(8 \mathrm{mg})$. The samples were then annealed at $450^{\circ} \mathrm{C}$ (Lenton furnace) in air for $2 \mathrm{~h}$ (ramp up $2^{\circ} \mathrm{C} \mathrm{min}^{-1}$ and ramp down $2^{\circ} \mathrm{C}$ $\left.\min ^{-1}\right)$.

\subsection{Photocatalytic reactor}

The gas phase stainless steel T-shaped reactor was composed of ultra-high vacuum (UHV) parts (Swagelok and Kurt J. Lesker) with an internal volume of $120 \mathrm{~mL}$. The reactor was fitted with a quartz window to allow irradiation of the catalyst plates. The catalyst plates were placed inside the reactor facing the quartz window. A schematic of the reactor is given in figure 1. High purity water (Merck, SupraSolv 7732-18-5) was added to the reactor at the start of each experiment. A magnetic flea with stirrer was used to give mixing within the reactor. The temperature of the reactor was maintained with thermostatically controlled thermal tape at $70^{\circ} \mathrm{C}$. The reactor was purged for $10 \mathrm{~min}$ with the feed gas mixture before sealing at a pressure of 2 bar. The feed gases for the reactor were $\mathrm{CO}_{2}(\mathrm{BOC}, \mathrm{UN1013}$, 99.99\% purity) and $\operatorname{Ar}$ (BOC, UN1006, 99.998\% purity).

The gaseous products obtained following irradiation was analysed by gas chromatography (GC) with a flame ionisation detector (FID) and using He (BOC, UN1046, 99.999\% purity) as a carrier gas. The GC (Agilent Technologies, 7890B) was connected directly to the reactor outlet and samples were analysed every 30 min leading to a decrease in pressure inside the reactor $(0.25$ bar) each time a measurement was performed. Sampling from the reactor following the initial purge and fill cycle were denoted $T_{0}$, time zero with later samples denoted $T_{30}, T_{60}$ etc to detail the number of minutes elapsed from irradiation. The $T_{0}$ sample act as reference point for the purity and mixture of gasses present prior to initiation of reaction by irradiation. The reactor was purged and filled with a range of gas mixtures to provide conditions for $\mathrm{CO}_{2}$ reduction, sample cleaning or absence of $\mathrm{CO}_{2}$ control runs. 


\section{3. $\mathrm{CO}_{2}$ reduction}

A mixture of $\mathrm{CO}_{2}: \mathrm{Ar}(20: 80)$ was used to test $\mathrm{CO}_{2}$ reduction in all experiments. This mixture was purged through the reactor prior to sealing the system at 2 bar with periodic sampling the gas mixture used to assess the generation of $\mathrm{CO}_{2}$ reduction products. These tests were performed on fresh photocatalyst samples or following control runs, the conditions of which are detailed below.

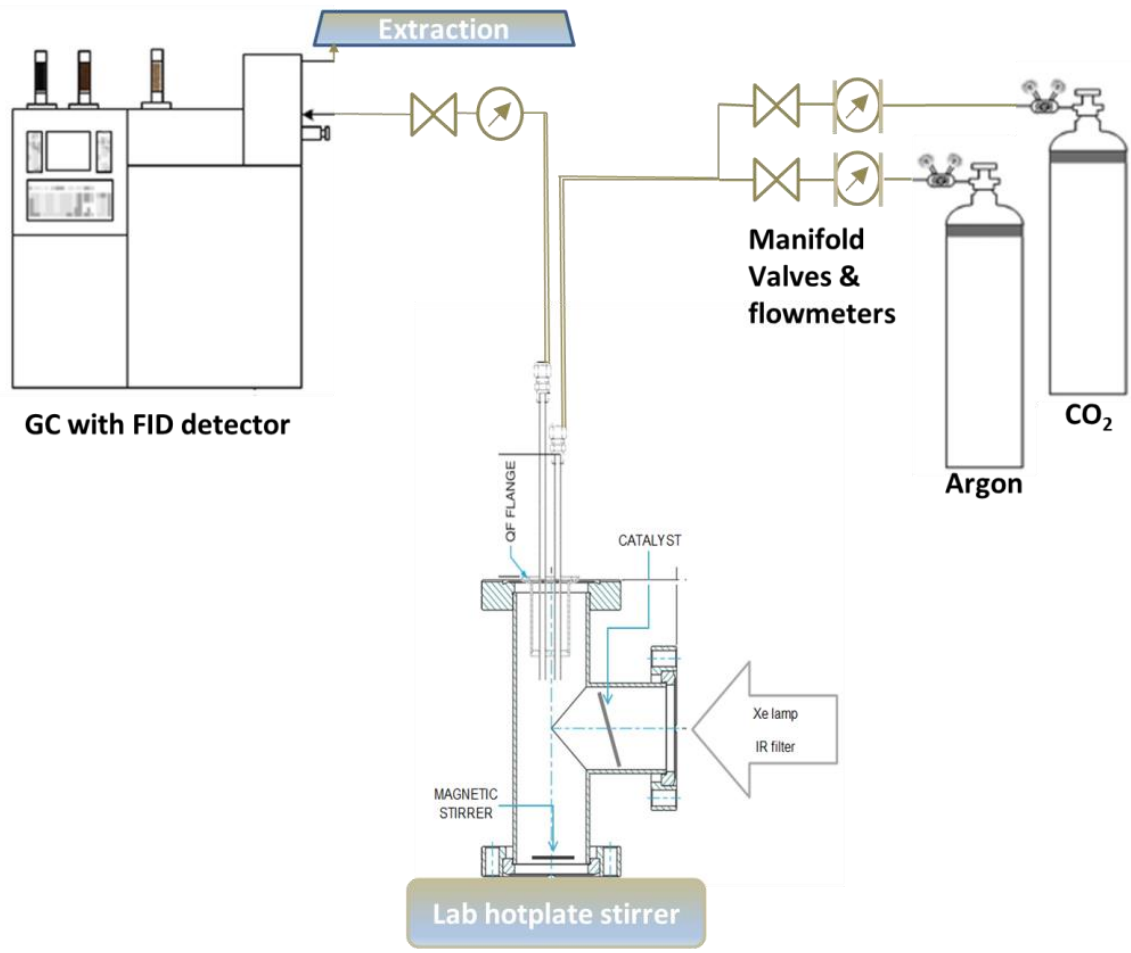

Fig. 1. Schematic diagram of the photocatalytic reaction apparatus

Control experiments in the absence of $\mathrm{CO}_{2}$ were performed for each catalyst. For these experiments, the reactor conditions were the same as for $\mathrm{CO}_{2}$ photoreduction; however, $100 \% \operatorname{Ar}$ was used for the purging and filling the reactor, in the presence of $200 \mu \mathrm{L}$ of water. Due to the inverse relationship between gas solubility and temperature, experiments with hot water were performed to try to further eliminate $\mathrm{CO}_{2}$ presence in the reactor for the control experiments. The procedure for each water condition added is detailed below:

- Cold water control: for all photocatalysts, room temperature deionised water was added to the reactor and it was heated after closing it.

- Hot water control: in this case, the water was heated to boiling before being added to the reactor that was already at $70^{\circ} \mathrm{C}$. This process was carried out in control tests with P25 and NTs as photocatalysts.

\subsection{Irradiation source and formal quantum efficiency}

The photocatalytic reactor was irradiated with a Xe lamp (100 W, LOT Oriel) through a water IR filter. The spectral intensity incident on the reactor window was measured with a calibrated spectral radiometer consisting of Jobin Yvon Horiba Gemini 120 monochromator 
and a SpectrAcq2 photomultiplier tube. The irradiance spectrum of the source is given in the supplementary information (Figure S1).

When using a polychromatic emission source the Formal Quantum Efficiencies (QE) should be reported [33]. The Formal Quantum efficiency is calculated using equation 1.

$$
Q E=\frac{\text { moles of electrons passed to form products }}{\text { moles of photons }(250-410 \mathrm{~nm}, \text { Einsteins })}
$$

It was assumed that wavelengths $>410 \mathrm{~nm}$ were not utilised by the photocatalytic materials based on previous photoelectrochemical studies determining the effective band gap [31].

\section{Results and discussion}

\subsection{Photocatalytic reduction of $\mathrm{CO}_{2}$}

Photocatalysts materials were tested for the photocatalytic reduction of $\mathrm{CO}_{2}$ using P25 as a bench mark reference. Controls in the absence of $\mathrm{CO}_{2}$ were also performed for each photocatalyst. When using P25 as a photocatalyst, both $\mathrm{CO}$ and $\mathrm{CH}_{4}$ products were observed with concentrations above the limit of detection (1.78 and $1.08 \mathrm{ppm}$ respectively) after $4 \mathrm{~h}$ of irradiation (Fig $2(a-b))$. However, as it can be seen in figure $2(a-b)$, similar concentrations were obtained when performing the controls in the absence of $\mathrm{CO}_{2}$ in the feed gas (1.51 ppm for $\mathrm{CO}$ and $0.71 \mathrm{ppm}$ for $\mathrm{CH}_{4}$ ). 

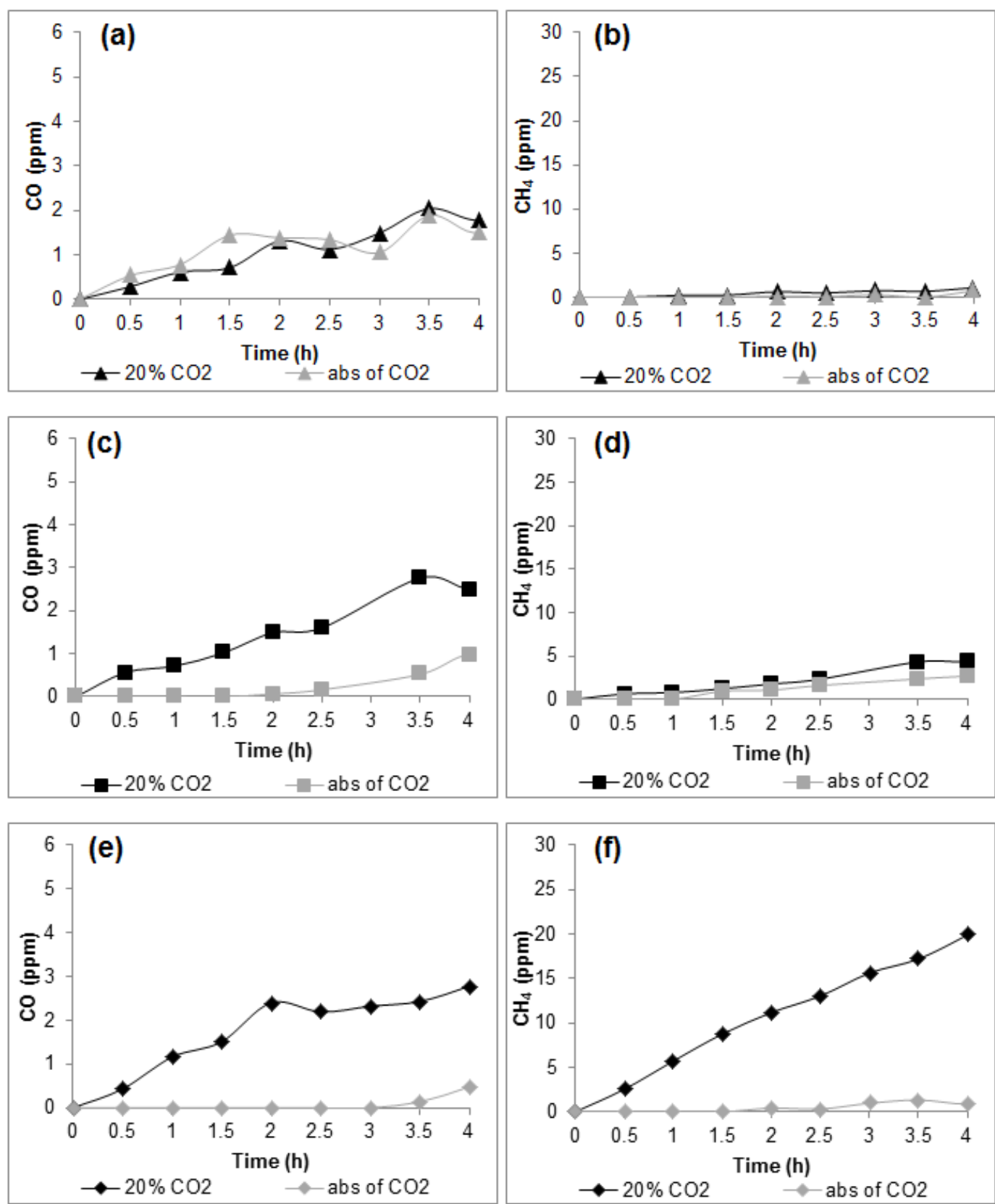

Fig. 2. $\mathrm{CO}$ and $\mathrm{CH}_{4}$ production (in ppm) over time using different catalysts in the presence and absence of $\mathrm{CO}_{2}$. (a-b) $\mathrm{TiO}_{2}$ (P25), (c-d) $\mathrm{Cu}-\mathrm{TiO}_{2}$, (e-f) NT

Copper modified P25, previously investigated as a water splitting catalyst [31], was used under identical reactor conditions (fig. 2, (c-d)). We reported the physicochemical properties of the $\mathrm{Cu}-\mathrm{TiO}_{2}$ previously where the average size of the copper clusters was $\sim 0.8-0.9 \mathrm{~nm}$, which was measured with STEM (scanning transmission electron microscopy) at a spot size of $0.2 \mathrm{~nm}$ [31]. XPS analysis showed that the copper clusters were a mixture of $\mathrm{Cu}(0)$ and $\mathrm{Cu}(\mathrm{I})$ after loading onto the $\mathrm{TiO}_{2}$ and annealing. In that work there was evidence of a small red shift in the effective band gap following Cu modification. Using incident photon to current conversion efficiency measurements, the effective band gap of unmodified P25 was $2.96 \mathrm{eV}$ and for the Cu doped P25 the band gap was $2.85 \mathrm{eV}$ equating to a small red-shift of $0.11 \mathrm{eV}$ $(16 \mathrm{~nm})$. This small red shift may result in a small improvement in solar driven $\mathrm{CO}_{2}$ reduction. 
The $\mathrm{Cu}-\mathrm{TiO}_{2}$ was observed to yield higher concentrations of both products, $\mathrm{CO}$ and $\mathrm{CH}_{4}$, (2.51 and $4.36 \mathrm{ppm}$, respectively) when compared to unmodified P25. The photocatalytic activity of $\mathrm{Cu}-\mathrm{TiO}_{2}$ was also tested in the absence of $\mathrm{CO}_{2}$. For both $\mathrm{CO}$ and $\mathrm{CH}_{4}$, the yields obtained in the absence of $\mathrm{CO}_{2}$ were significantly lower than in the presence of $\mathrm{CO}_{2}(\mathrm{CO}=$ $0.96 \mathrm{ppm}$ and $\mathrm{CH}_{4}=2.7 \mathrm{ppm}$ ).

$\mathrm{TiO}_{2}$ nanotubes (NT) were also tested as photocatalysts for $\mathrm{CO}_{2}$ photoreduction (fig. 2 (e-f)). The NT were produced by a hydrothermal method previously reported [32] which gave tubes with an inner diameter between 4-6 nm and an outer diameter between 8-12 nm respectively. In that work, XRD analysis showed that the tubes were predominantly anatase $\mathrm{TiO}_{2}$. Tubes annealed at $400^{\circ} \mathrm{C}$ were mesoporous with pore sizes between 2 and $50 \mathrm{~nm}$, where a pore size less than $10 \mathrm{~nm}$ corresponded to the inner diameter of the nanotubes and the larger pores (10-100 nm) were attributed to the aggregation of the nanotubes.

In terms of $\mathrm{CO}$ production, the results were similar to the ones obtained with $\mathrm{Cu}-\mathrm{TiO}_{2}(2.78$ ppm). The NTs proved to be more efficient for $\mathrm{CH}_{4}$ production than the other two photocatalysts tested, obtaining a concentration of $19.89 \mathrm{ppm}$ after $4 \mathrm{~h}$ of irradiation. When the control experiments were performed in the absence of $\mathrm{CO}_{2}$, the $\mathrm{CO}$ and $\mathrm{CH}_{4}$ concentrations yielded were much lower than in the presence of $\mathrm{CO}_{2}(0.48 \mathrm{ppm}$ for $\mathrm{CO}$ and $0.87 \mathrm{ppm}$ for $\mathrm{CH}_{4}$ ). The presence of small quantities of $\mathrm{CO}_{2}$ reduction products in the absence of $\mathrm{CO}_{2}$ in the gas feed prompted an investigation into sources of trace $\mathrm{CO}_{2}$ in the reactor.

\subsection{Additional controls in the absence of $\mathrm{CO}_{2}$}

Calculation of $\mathrm{CO}_{2}$ peak areas in $\mathrm{GC}$ at $\mathrm{T}_{0}$ for $\mathrm{CO}_{2}$ control measurements showed a very low concentration of $\mathrm{CO}_{2}$ to be present, in the $\sim 10-20 \mu \mathrm{Mol}$ range. A calculation of the amount of $\mathrm{CO}_{2}$ potentially dissolved in the feed water added to the reactor yielded a value $\sim 8 \mu \mathrm{Mol}$ as a possible source for the concentrations observed in GC analysis of $T_{0}$ samples. Control experiments in the absence of $\mathrm{CO}_{2}$ in the feed gas were repeated where the feed water was pre-boiled to remove dissolved $\mathrm{CO}_{2}$. With pre-boiled feed water, the peak area for $\mathrm{CO}_{2}$ at $\mathrm{T}_{0}$ was half that observed with non-treated water (12.5 and $4.4 \mu \mathrm{Mol}$ respectively). 

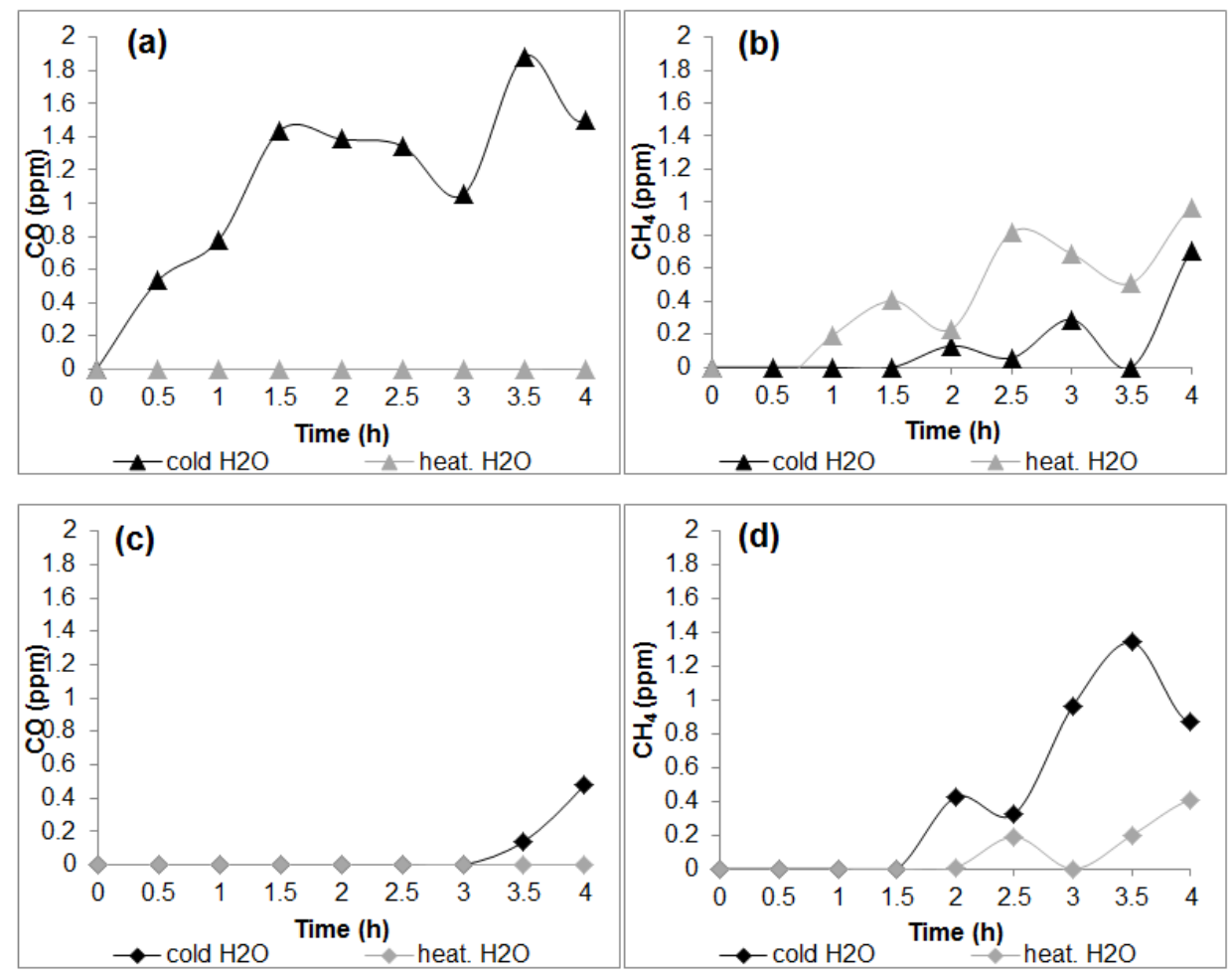

Fig. 3. $\mathrm{CO}$ and $\mathrm{CH}_{4}$ production (in ppm) over time in the controls in the absence of $\mathrm{CO}_{2}$ performed with addition of cold or of heated water. (a-b) P25, (c-d) NT

With small quantities of $\mathrm{CO}_{2}$ still being present in hot water, the control in the absence of $\mathrm{CO}_{2}$ in the feed gas gave much smaller amounts of $\mathrm{CO}$ and $\mathrm{CH}_{4}$ (see fig 3). With the P25 control (fig. 3. (a-b)), both the hot water and the cold water concentrations for $\mathrm{CH}_{4}$ production were below or close to the detection limit $(0.75 \mathrm{ppm})$ and cannot be considered as significant. For the NT samples, the $\mathrm{CH}_{4}$ concentrations obtained with cold water added are above the limit of detection after $3 \mathrm{~h}$ of irradiation but with heated water the $\mathrm{CH}_{4}$ produced is below the detection limit. For the NTs and cold water, CO production is observed above the detection limit (1.58 ppm) after $3.5 \mathrm{~h}$ of irradiation but with heated water the $\mathrm{CO}$ production is below the detection limit. Some authors have suggested that a precleaning step is necessary to ensure the adsorption sites, and therefore potential active sites, are not occupied [34, 35].

When performing the control experiments in the absence of $\mathrm{CO}_{2}$ in the feed gas, with NTs as the photocatalyst, adding pre-boiled water resulted in a lower initial concentration of $\mathrm{CO}_{2}$ of $6.7 \mu \mathrm{Mol}$ at $\mathrm{T}_{0}$ when compared with control with non pre-boiled water $\left(18.2 \mu \mathrm{Mol}\right.$ at $\left.\mathrm{T}_{0}\right)$.

It is difficult to remove all $\mathrm{CO}_{2}$ from the reactor. Although using pre-boiled feed water reduced the detected $\mathrm{CO}_{2}$ at $\mathrm{T}_{0}$, a small but still detectable peak for $\mathrm{CO}_{2}$ remained. The source of this $\mathrm{CO}_{2}$ is not immediately obvious as the reactor was purged with argon (99.998\% purity, possibly 20 ppm unknown) and the water degassed. Due to equilibrium with $\mathrm{CO}_{2}$ in the atmosphere, $\mathrm{CO}_{2}$ as bicarbonate monolayer coverage have previously been observed [21]. We have observed changes to carbonate type, bicarbonate carbonate equilibrium, under differing surface treatments and photocatalytic conditions [35-37]. Previous studies on carbonates as a source of $\mathrm{CO}_{2}$ reduction products have argued that 
decomposition of carbonates are more likely to lead to $\mathrm{CO}_{2}$ rather than reduced products [35]. Decomposition of surface carbonates may yield $\mathrm{CO}_{2}$. Indeed, if the surface of the catalyst is contaminated with low levels of organic carbon impurities, photocatalytic oxidation of these compounds would release $\mathrm{CO}_{2}$.

\subsection{Yields and Formal Quantum Efficiency}

To compare the product yields obtained in this study with those of other researchers, caution should be taken as the yields obtained can be heavily influenced by reactor geometry and conditions employed. In this regard, the comparative yields given in table 1 were made with reported reactors using the same volume and type of light source to minimise the influence of reaction conditions. However, even when comparing similar reactors and conditions, many researchers normalise their results to a yield per gram of photocatalyst, which can be misleading, biasing the result towards reactors that utilise smaller amounts of catalyst e.g. thin films. This comparison is even more complicated when no data is provided to show whether product yields scale linearly with catalyst loading (and the assumption that the product yield will increase upon increasing photocatalyst loading may not be easily engineered to maintain the same irradiated photocatalyst area or mass). In addition, this normalised photocatalytic reaction rate is often measured as an average over a number of hours, despite the reaction kinetics changing over this time period for some materials.

The yields reported by others cannot be directly compared as there are differences in reactor systems, although the yields reported by others in terms of $\mu \mathrm{mol} \mathrm{h}^{-1} \mathrm{~g}^{-1}$ cat are within one order of magnitude to those observed in this work (Table 1). Zhai et al. [38], reported higher yields of $\mathrm{CO}$ and $\mathrm{CH}_{4}$ for both $\mathrm{P} 25$ and $\mathrm{Cu}-\mathrm{TiO}_{2}$, however they used a $200 \mathrm{~W}$ Xe source whereas in this work we used a $100 \mathrm{~W}$ Xe source. Zhai et al. did not report the light intensity entering the reactor or the area of catalyst irradiated, nor do they calculate formal quantum yield. The irradiance will be a dominant factor controlling the yield [39]. Gonell et al. [40] reported a range of yields for $\mathrm{CO}$ and $\mathrm{CH}_{4}$ using $\mathrm{Cu}-\mathrm{TiO}_{2}$ in a water based solvent system with and without electron donor. In the presence of electron donor, they observed the highest yield of $\mathrm{CO}$, no $\mathrm{CH}_{4}$ and increased yields for $\mathrm{H}_{2}$. The use of different reactor systems and different irradiance sources means that direct comparison of results is impossible and strongly supports the need for standardised systems or conditions for comparison of results for photocatalytic $\mathrm{CO}_{2}$ reduction.

The reporting of Photonic Efficiency (Apparent Quantum Yield) for monochromatic sources, or Formal Quantum Efficiency (FQE) for polychromatic sources, is more appropriate for correlation of results from different groups. In the present work the FQE for each photocatalyst were calculated according to equation 1 (the irradiance of the source is given in figure S1) and are given in table 1. 
Table 1: Product yields after $4 \mathrm{~h}$ of irradiation and formal quantum efficiency (Q.E) obtained in this work vs yields and quantum efficiency observed in the literature (under comparable reactor conditions)

\begin{tabular}{|c|c|c|c|c|c|c|c|c|}
\hline \multirow[t]{2}{*}{ Catalyst } & \multicolumn{2}{|c|}{$\begin{array}{l}\text { Ref. Yields }\left(\mu \mathrm{mol} \mathrm{h}^{-1}\right. \\
\left.\mathrm{g}^{-1} \text { cat }\right)\end{array}$} & \multirow[t]{2}{*}{ Ref. } & \multicolumn{2}{|c|}{$\begin{array}{l}\text { Yields obtained } \\
\text { in this work } \\
\left(\mu \mathrm{mol} \mathrm{h} \mathrm{h}^{-1} \mathrm{~g}^{-1} \text { cat }\right)\end{array}$} & \multicolumn{3}{|c|}{$\begin{array}{c}\text { Formal Q.E } \\
(250-410 \mathrm{~nm})\end{array}$} \\
\hline & $\mathrm{CO}$ & $\mathrm{CH}_{4}$ & & $\mathrm{CO}$ & $\mathrm{CH}_{4}$ & $\mathrm{CO}$ & $\mathrm{CH}_{4}$ & $\mathrm{CO}_{2}$ \\
\hline P25 & 1.2 & 0.38 & [41] & \multirow{2}{*}{0.41} & \multirow{2}{*}{0.25} & \multirow{2}{*}{$1.29 \times 10^{-5}$} & \multirow{2}{*}{$3.12 \times 10^{-5}$} & \multirow{2}{*}{$4.41 \times 10^{-5}$} \\
\hline P25 & 2.5 & 1.2 & \multirow{2}{*}{ [38] } & & & & & \\
\hline \multirow{2}{*}{$\mathrm{Cu}-\mathrm{TiO}_{2}$} & 5.4 & 8.7 & & \multirow{2}{*}{0.58} & \multirow{2}{*}{1.01} & \multirow{2}{*}{$1.82 \times 10^{-5}$} & \multirow{2}{*}{$1.26 \times 10^{-4}$} & \multirow{2}{*}{$1.44 \times 10^{-4}$} \\
\hline & $0.3-2.8^{*}$ & $0-0.3^{*}$ & [40] & & & & & \\
\hline NT & - & 1.48 & [32] & 0.64 & 4.61 & $2.01 \times 10^{-5}$ & $5.75 \times 10^{-4}$ & $5.95 \times 10^{-4}$ \\
\hline
\end{tabular}

${ }^{a}$ Gonell et al [40] report a range of values for $\mathrm{CO}$ and $\mathrm{CH}_{4}$ yield in a liquid phase reactor with different solvents and with/without electron donor. With electron donor no $\mathrm{CH}_{4}$ was produced and increased yields $\mathrm{CO}$ and $\mathrm{H}_{2}$ were observed.

As it can be seen in table 1, the calculated FQE obtained for $\mathrm{CO}$ and $\mathrm{CH}_{4}$ products are very low, as are the overall FQE for $\mathrm{CO}_{2}$ reduction. The order of efficiency for $\mathrm{CO}, \mathrm{CH}_{4}$ production and overall $\mathrm{CO}_{2}$ reduction was $\mathrm{NT}>\mathrm{Cu}-\mathrm{TiO}_{2}>\mathrm{P} 25$. The modification of the P25 with $\mathrm{Cu}$ clusters (mixed oxidation state of $\mathrm{Cu}(0)$ and $\mathrm{Cu}(1)$ ) gives a slight red shift in the effective band gap as previously reported [31]. $\mathrm{Cu}_{2} \mathrm{O}$ has a more negative conduction band edge that $\mathrm{TiO}_{2}$ (anatase or rutile) and this may lead to the slight improvement in the efficiency for $\mathrm{CO}_{2}$ reduction as compared to the unmodified P25 unmodified. Hori (2008) reported that for the electrochemical reduction of $\mathrm{CO}_{2}$, copper had a higher affinity to produce hydrocarbons, when compared to other metals [42], but was also able to produce $\mathrm{CO}$. The major difference in the efficiency of the materials observed in this work was the enhanced yield of $\mathrm{CH}_{4}$ observed with the $\mathrm{TiO}_{2}$ NTs as compared to $\mathrm{Cu}-\mathrm{TiO}_{2}$ and $\mathrm{P} 25$. In previous work it was reported that enhanced efficiency for $\mathrm{CO}_{2}$ reduction on NTs was due to a high concentration of undercoordinated titanium sites, which was supported by EPR analysis [32].

The quantum efficiency of photocatalytic $\mathrm{CO}_{2}$ reduction is rarely reported. However, in the cases it has been calculated, the efficiency is typically very low [43-45]. To understand the typically low efficiencies observed during photocatalytic $\mathrm{CO}_{2}$ reduction the current understanding of the mechanism by which $\mathrm{CO}_{2}$ generates these products and alternative back or side reactions should be considered. There are a number of $\mathrm{CO}_{2}$ pathways named after key intermediates, formaldehyde [46, 47], carbene [48] and glyoxal pathways [18, 35], reported to explain the steps in $\mathrm{CO}_{2}$ reduction to the commonly observed products, methane, methanol, carbon monoxide etc. All of these pathways assumes the single electron reduction of $\mathrm{CO}_{2}$ to $\mathrm{CO}_{2}-$, although this reaction is high energy step requiring a very negative electrochemical potential [35] which is either too negative to be achieved with the conduction band of most of the photocatalysts reported or, if achievable, leaves limited overpotential to drive this reaction. All of these potential mechanisms have been investigated under ultra-pure conditions $[18,35,49]$ and none of the mechanisms were considered to be representative of all the steps occurring in photocatalytic $\mathrm{CO}_{2}$ reduction. However these reports did show that the glyoxal pathway may occur, but is likely a minor path, with an alternative undiscovered pathway leading to acetaldehyde postulated [35]. One interesting aspect of the glyoxal pathway and the alternative path through acetaldehyde differing from the carbene or formaldehyde pathways is both of these newer pathways require 
intermediates that are generated by oxidation reactions. If the glyoxal pathway or a newer pathway incorporating some of its steps is shown to be the correct mechanism, by which photocatalytic $\mathrm{CO}_{2}$ reduction occurs, then low efficiency reported may be an artefact due to incorrectly addressing the number of electrons required to reduce $\mathrm{CO}_{2}$. One aspect considered in glyoxal pathway that may also explain the low efficiencies reported is the degree of back reaction i.e., re-oxidation of reduced $\mathrm{CO}_{2}$ products by valence band holes. $\mathrm{A}$ recent study to this effect observed that photocatalysts that were good at degrading ethane, ethylene or methane were poor reducing $\mathrm{CO}_{2}$, whereas photocatalysts that were modified to reduce the efficiency for oxidising these compounds showed improved yields of these $\mathrm{CO}_{2}$ reduction products suggesting that blocking re-oxidation of products may be a route to improving activity for $\mathrm{CO}_{2}$ reduction [50]. Considering that re-oxidation of $\mathrm{CO}_{2}$ reduction products and intermediates has been observed, these back reactions may explain the low efficiencies often observed in photocatalytic $\mathrm{CO}_{2}$ reduction.

\section{Conclusions}

Improvement in the activity for photocatalytic reduction of $\mathrm{CO}_{2}$ was observed following surface modification using $\mathrm{Cu}$ clusters, or nanoengineering of the titania to give nanotubes. These modification strategies studied, showed increases in yields consistent with previous reports in the literature. The order of efficiency for $\mathrm{CO}, \mathrm{CH}_{4}$ production and overall $\mathrm{CO}_{2}$ reduction was $\mathrm{NT}>\mathrm{Cu}-\mathrm{TiO}_{2}>\mathrm{P} 25$. Formal Quantum Efficiencies were determined for the photocatalytic reduction of $\mathrm{CO}_{2}$ and showed that even where reasonable product yields were observed, as compared to literature, the FQE were very low. Of the photocatalysts tested in this study, the nanotubes prepared using a hydrothermal route, showed a marked improvement in $\mathrm{CH}_{4}$ production as compared to the $\mathrm{Cu}-\mathrm{TiO}_{2}$ and the unmodified P25.

\section{Acknowledgements}

We wish to acknowledge funding from the US-Ireland R\&D Collaborative Partnership Program NSF (CBET-1438721), SFI (SFI 14/US/E2915) and DfE (USI065) and the financial support from British Council under the STREAM-MENA Institutional Links Scheme (Grant number 278072873).

\section{References:}

[1] O. Ola, M.M. Maroto-Valer, Review of material design and reactor engineering on TiO2 photocatalysis for $\mathrm{CO} 2$ reduction, Journal of Photochemistry and Photobiology C: Photochemistry Reviews, 24 (2015) 16-42.

[2] K. Li, X. An, K.H. Park, M. Khraisheh, J. Tang, A critical review of CO2 photoconversion: Catalysts and reactors, Catalysis Today, 224 (2014) 3-12.

[3] P. Akhter, M. Hussain, G. Saracco, N. Russo, Novel nanostructured-TiO2 materials for the photocatalytic reduction of $\mathrm{CO} 2$ greenhouse gas to hydrocarbons and syngas, 2015.

[4] C. Finn, S. Schnittger, L.J. Yellowlees, J.B. Love, Molecular approaches to the electrochemical reduction of carbon dioxide, Chemical Communications, 48 (2012) 13921399.

[5] J.L. White, M.F. Baruch, J.E. Pander lii, Y. Hu, I.C. Fortmeyer, J.E. Park, T. Zhang, K. Liao, J. Gu, Y. Yan, T.W. Shaw, E. Abelev, A.B. Bocarsly, Light-Driven Heterogeneous 
Reduction of Carbon Dioxide: Photocatalysts and Photoelectrodes, Chemical Reviews, 115 (2015) 12888-12935.

[6] M. Pelaez, N.T. Nolan, S.C. Pillai, M.K. Seery, P. Falaras, A.G. Kontos, P.S.M. Dunlop, J.W.J. Hamilton, J.A. Byrne, K. O'Shea, M.H. Entezari, D.D. Dionysiou, A review on the visible light active titanium dioxide photocatalysts for environmental applications, Applied Catalysis B: Environmental, 125 (2012) 331-349.

[7] T. Yui, A. Kan, C. Saitoh, K. Koike, T. Ibusuki, O. Ishitani, Photochemical Reduction of CO2 Using TiO2: Effects of Organic Adsorbates on TiO2 and Deposition of Pd onto TiO2, ACS Applied Materials \& Interfaces, 3 (2011) 2594-2600.

[8] K. lizuka, T. Wato, Y. Miseki, K. Saito, A. Kudo, Photocatalytic Reduction of Carbon Dioxide over Ag Cocatalyst-Loaded ALa4Ti4O15 (A = Ca, Sr, and $\mathrm{Ba}$ ) Using Water as a Reducing Reagent, Journal of the American Chemical Society, 133 (2011) 20863-20868.

[9] Q. Kang, T. Wang, P. Li, L. Liu, K. Chang, M. Li, J. Ye, Photocatalytic Reduction of Carbon Dioxide by Hydrous Hydrazine over $\mathrm{Au}-\mathrm{Cu}$ Alloy Nanoparticles Supported on SrTiO3/TiO2 Coaxial Nanotube Arrays, Angewandte Chemie International Edition, 54 (2015) 841-845.

[10] Y.-X. Pan, Z.-Q. Sun, H.-P. Cong, Y.-L. Men, S. Xin, J. Song, S.-H. Yu, Photocatalytic $\mathrm{CO} 2$ reduction highly enhanced by oxygen vacancies on Pt-nanoparticle-dispersed gallium oxide, Nano Research, 9 (2016) 1689-1700.

[11] F. Sastre, A.V. Puga, L. Liu, A. Corma, H. García, Complete Photocatalytic Reduction of $\mathrm{CO} 2$ to Methane by $\mathrm{H} 2$ under Solar Light Irradiation, Journal of the American Chemical Society, 136 (2014) 6798-6801.

[12] K. Teramura, S. Iguchi, Y. Mizuno, T. Shishido, T. Tanaka, Photocatalytic Conversion of CO2 in Water over Layered Double Hydroxides, Angewandte Chemie, 124 (2012) 8132 8135.

[13] C.-C. Yang, Y.-H. Yu, B. van der Linden, J.C.S. Wu, G. Mul, Artificial Photosynthesis over Crystalline TiO2-Based Catalysts: Fact or Fiction?, Journal of the American Chemical Society, 132 (2010) 8398-8406.

[14] B. AlOtaibi, X. Kong, S. Vanka, S.Y. Woo, A. Pofelski, F. Oudjedi, S. Fan, M.G. Kibria, G.A. Botton, W. Ji, H. Guo, Z. Mi, Photochemical Carbon Dioxide Reduction on Mg-Doped $\mathrm{Ga}(\mathrm{In}) \mathrm{N}$ Nanowire Arrays under Visible Light Irradiation, ACS Energy Letters, 1 (2016) 246252.

[15] H.-C. Hsu, I. Shown, H.-Y. Wei, Y.-C. Chang, H.-Y. Du, Y.-G. Lin, C.-A. Tseng, C.-H. Wang, L.-C. Chen, Y.-C. Lin, K.-H. Chen, Graphene oxide as a promising photocatalyst for CO2 to methanol conversion, Nanoscale, 5 (2013) 262-268.

[16] S. Iguchi, K. Teramura, S. Hosokawa, T. Tanaka, Photocatalytic conversion of CO2 in an aqueous solution using various kinds of layered double hydroxides, Catalysis Today, 251 (2015) 140-144.

[17] S. Wang, X. Wang, Photocatalytic CO2 reduction by CdS promoted with a zeolitic imidazolate framework, Applied Catalysis B: Environmental, 162 (2015) 494-500.

[18] I.A. Shkrob, T.W. Marin, H. He, P. Zapol, Photoredox Reactions and the Catalytic Cycle for Carbon Dioxide Fixation and Methanogenesis on Metal Oxides, The Journal of Physical Chemistry C, 116 (2012) 9450-9460.

[19] W. Chanmanee, M.F. Islam, B.H. Dennis, F.M. MacDonnell, Solar photothermochemical alkane reverse combustion, Proceedings of the National Academy of Sciences, 113 (2016) 2579.

[20] Retraction for Chanmanee et al., Solar photothermochemical alkane reverse combustion, Proceedings of the National Academy of Sciences, 115 (2018) E557.

[21] A. Song, E.S. Skibinski, W.J.I. DeBenedetti, A.G. Ortoll-Bloch, M.A. Hines, Nanoscale Solvation Leads to Spontaneous Formation of a Bicarbonate Monolayer on Rutile (110) under Ambient Conditions: Implications for $\mathrm{CO} 2$ Photoreduction, The Journal of Physical Chemistry C, 120 (2016) 9326-9333.

[22] I.H. Tseng, W.-C. Chang, J.C.S. Wu, Photoreduction of $\mathrm{CO} 2$ using sol-gel derived titania and titania-supported copper catalysts, Applied Catalysis B: Environmental, 37 (2002) 37-48. 
[23] W.-N. Wang, W.-J. An, B. Ramalingam, S. Mukherjee, D.M. Niedzwiedzki, S. Gangopadhyay, P. Biswas, Size and Structure Matter: Enhanced CO2 Photoreduction Efficiency by Size-Resolved Ultrafine Pt Nanoparticles on TiO2 Single Crystals, Journal of the American Chemical Society, 134 (2012) 11276-11281.

[24] J.C.S. Wu, T.-H. Wu, T. Chu, H. Huang, D. Tsai, Application of Optical-fiber Photoreactor for CO2 Photocatalytic Reduction, Topics in Catalysis, 47 (2008) 131-136.

[25] P.-Y. Liou, S.-C. Chen, J.C.S. Wu, D. Liu, S. Mackintosh, M. Maroto-Valer, R. Linforth, Photocatalytic $\mathrm{CO} 2$ reduction using an internally illuminated monolith photoreactor, Energy \& Environmental Science, 4 (2011) 1487-1494.

[26] O. Ola, M. Maroto-Valer, D. Liu, S. Mackintosh, C.-W. Lee, J.C.S. Wu, Performance comparison of $\mathrm{CO} 2$ conversion in slurry and monolith photoreactors using $\mathrm{Pd}$ and $\mathrm{Rh}-\mathrm{TiO} 2$ catalyst under ultraviolet irradiation, Applied Catalysis B: Environmental, 126 (2012) 172179.

[27] W.-H. Lee, C.-H. Liao, M.-F. Tsai, C.-W. Huang, J.C.S. Wu, A novel twin reactor for $\mathrm{CO} 2$ photoreduction to mimic artificial photosynthesis, Applied Catalysis B: Environmental, 132-133 (2013) 445-451.

[28] T.-V. Nguyen, J.C.S. Wu, Photoreduction of CO2 to fuels under sunlight using opticalfiber reactor, Solar Energy Materials and Solar Cells, 92 (2008) 864-872.

[29] L. Collado, P. Jana, B. Sierra, J.M. Coronado, P. Pizarro, D.P. Serrano, V.A. de la Peña O'Shea, Enhancement of hydrocarbon production via artificial photosynthesis due to synergetic effect of $\mathrm{Ag}$ supported on $\mathrm{TiO} 2$ and $\mathrm{ZnO}$ semiconductors, Chemical Engineering Journal, 224 (2013) 128-135.

[30] M. Tahir, N.S. Amin, Photocatalytic CO2 reduction and kinetic study over In/TiO2 nanoparticles supported microchannel monolith photoreactor, Applied Catalysis A: General, 467 (2013) 483-496.

[31] P.K. Sharma, M.A.L.R.M. Cortes, J.W.J. Hamilton, Y. Han, J.A. Byrne, M. Nolan, Surface modification of $\mathrm{TiO} 2$ with copper clusters for band gap narrowing, Catalysis Today, (2017).

[32] B. Vijayan, N.M. Dimitrijevic, T. Rajh, K. Gray, Effect of Calcination Temperature on the Photocatalytic Reduction and Oxidation Processes of Hydrothermally Synthesized Titania Nanotubes, The Journal of Physical Chemistry C, 114 (2010) 12994-13002.

[33] A. Mills, S. Le Hunte, An overview of semiconductor photocatalysis, Journal of Photochemistry and Photobiology A: Chemistry, 108 (1997) 1-35.

[34] M. Dilla, A. Mateblowski, S. Ristig, J. Strunk, Photocatalytic CO2 Reduction under Continuous Flow High-Purity Conditions: Influence of Light Intensity and H2O Concentration, ChemCatChem, 9 (2017) 4345-4352.

[35] A. Pougin, M. Dilla, J. Strunk, Identification and exclusion of intermediates of photocatalytic $\mathrm{CO} 2$ reduction on $\mathrm{TiO} 2$ under conditions of highest purity, Physical Chemistry Chemical Physics, 18 (2016) 10809-10817.

[36] K.C. Schwartzenberg, J.W.J. Hamilton, A.K. Lucid, E. Weitz, J. Notestein, M. Nolan, J.A. Byrne, K.A. Gray, Multifunctional photo/thermal catalysts for the reduction of carbon dioxide, Catalysis Today, 280 (2017) 65-73.

[37] K. Schwartzenberg, The Synthesis and Characterization of Multifunctional Titania-based Materials for the Photo/Thermal Catalytic Reduction of CO2, Civil and Environmental Engineering, Northwestern University, ProQuest Dissertations And Theses; Thesis (Ph.D.)-Northwestern University, 2015, pp. 1-166.

[38] Q. Zhai, S. Xie, W. Fan, Q. Zhang, Y. Wang, W. Deng, Y. Wang, Photocatalytic conversion of carbon dioxide with water into methane: platinum and copper (I) oxide cocatalysts with a core-shell structure, Angewandte Chemie, 125 (2013) 5888-5891.

[39] K. Kočí, L. Obalová, D. Plachá, Z. Lacný, Effect of temperature, pressure and volume of reacting phase on photocatalytic $\mathrm{CO} 2$ reduction on suspended nanocrystalline $\mathrm{TiO} 2$, Collection of czechoslovak chemical communications, 73 (2008) 1192-1204.

[40] F. Gonell, A.V. Puga, B. Julián-López, H. García, A. Corma, Copper-doped titania photocatalysts for simultaneous reduction of $\mathrm{CO} 2$ and production of $\mathrm{H} 2$ from aqueous sulfide, Applied Catalysis B: Environmental, 180 (2016) 263-270. 
[41] S. Xie, Y. Wang, Q. Zhang, W. Deng, Y. Wang, MgO- and Pt-Promoted TiO2 as an Efficient Photocatalyst for the Preferential Reduction of Carbon Dioxide in the Presence of Water, ACS Catalysis, 4 (2014) 3644-3653.

[42] Y.i. Hori, Electrochemical CO 2 reduction on metal electrodes, Modern aspects of electrochemistry, Springer2008, pp. 89-189.

[43] M. Tahir, N.S. Amin, Performance analysis of nanostructured NiO-In2O3/TiO2 catalyst for $\mathrm{CO} 2$ photoreduction with $\mathrm{H} 2$ in a monolith photoreactor, Chemical Engineering Journal, 285 (2016) 635-649.

[44] B.-J. Liu, T. Torimoto, H. Yoneyama, Photocatalytic reduction of carbon dioxide in the presence of nitrate using $\mathrm{TiO} 2$ nanocrystal photocatalyst embedded in $\mathrm{SiO} 2$ matrices, Journal of Photochemistry and Photobiology A: Chemistry, 115 (1998) 227-230.

[45] Y. Li, W.-N. Wang, Z. Zhan, M.-H. Woo, C.-Y. Wu, P. Biswas, Photocatalytic reduction of $\mathrm{CO} 2$ with $\mathrm{H} 2 \mathrm{O}$ on mesoporous silica supported $\mathrm{Cu} / \mathrm{TiO} 2$ catalysts, Applied Catalysis B: Environmental, 100 (2010) 386-392.

[46] M. Subrahmanyam, S. Kaneco, N. Alonso-Vante, A screening for the photo reduction of carbon dioxide supported on metal oxide catalysts for $\mathrm{C} 1-\mathrm{C} 3$ selectivity, Applied Catalysis B: Environmental, 23 (1999) 169-174.

[47] N. Sasirekha, S.J.S. Basha, K. Shanthi, Photocatalytic performance of Ru doped anatase mounted on silica for reduction of carbon dioxide, Applied Catalysis B: Environmental, 62 (2006) 169-180.

[48] M. Anpo, H. Yamashita, Y. Ichihashi, S. Ehara, Photocatalytic reduction of CO2 with $\mathrm{H} 2 \mathrm{O}$ on various titanium oxide catalysts, Journal of Electroanalytical Chemistry, 396 (1995) 21-26.

[49] I.A. Shkrob, N.M. Dimitrijevic, T.W. Marin, H. He, P. Zapol, Heteroatom-Transfer Coupled Photoreduction and Carbon Dioxide Fixation on Metal Oxides, The Journal of Physical Chemistry C, 116 (2012) 9461-9471.

[50] M.S. Hamdy, R. Amrollahi, I. Sinev, B. Mei, G. Mul, Strategies to Design Efficient SilicaSupported Photocatalysts for Reduction of CO2, Journal of the American Chemical Society, 136 (2014) 594-597. 
Supplementary Information

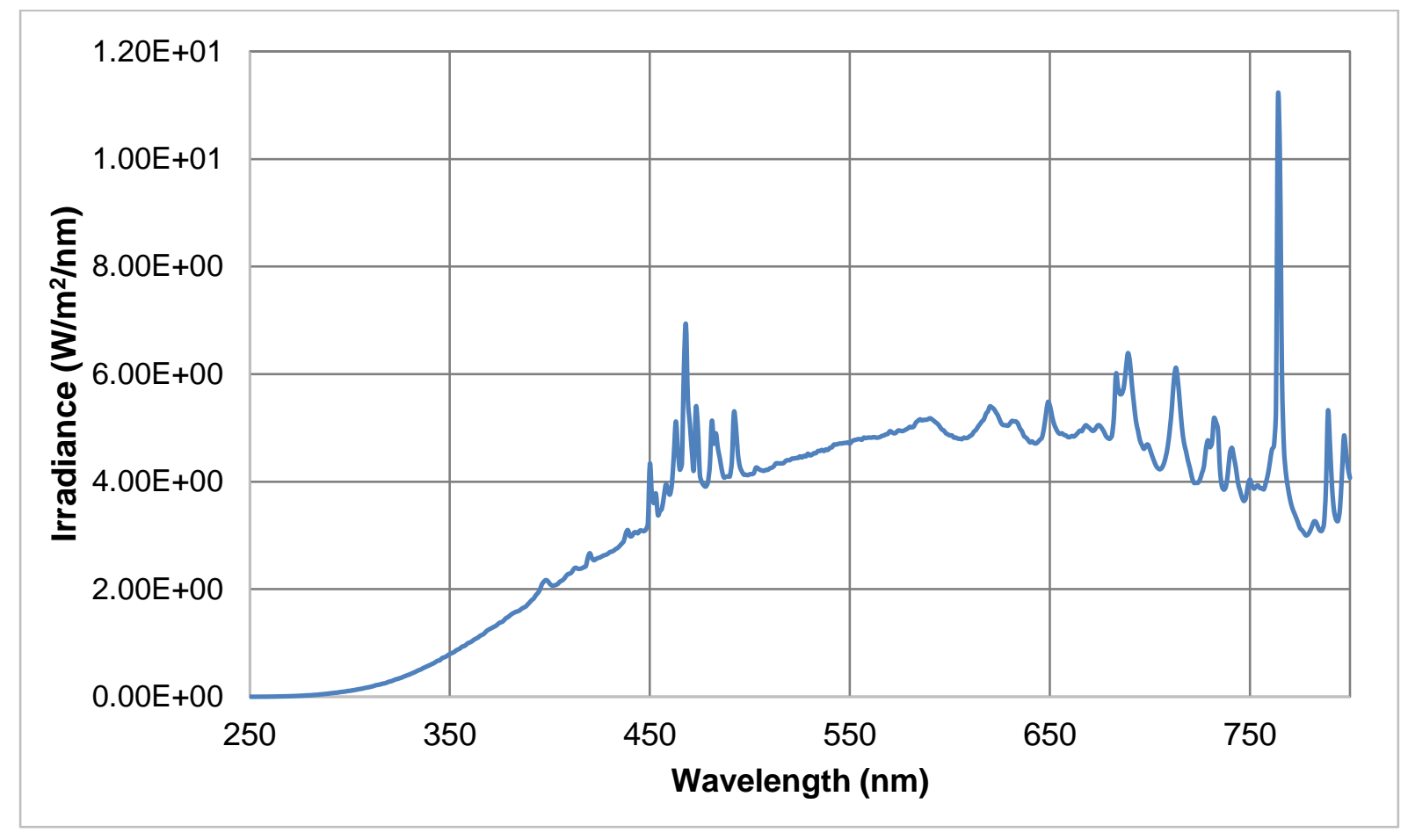

Figure S1 - Measured irradiance from 125W Xe lamp with IR filter 